E-JURNAL EKONOMI DAN BISNIS UNIVERSITAS UDAYANA
Available online at https://ojs.unud.ac.id/index.php/EEB/index
Vol. 10 No. 8 August 2021, pages: 674-680
e-ISSN: 2337-3067

\title{
PENGARUH PEMBERDAYAAN MASYARAKAT TERHADAP COMMUNITY BASED TOURISM DAN KESEJAHTERAAN MASYARAKAT PADA CEKING RICE TERRACE, TEGALLALANG
}

\author{
Adi Suryawan ${ }^{1}$ Made Suyana Utama ${ }^{2}$
}

Article history:

Submitted: 28 April 2021

Revised: 8 Mei 2021

Accepted: 25 Mei 2021

\section{Keywords:}

Community Welfare;

Community Empowerment;

Community Based Tourism;

\section{Kata Kunci:}

Kesejahteraan Masyarakat; Pemberdayaan Masyarakat; Community Based Tourism;

\section{Koresponding:}

Fakulas Ekonomi dan Bisnis Universitas Udayana, Bali, Indonesia

Email:

adisuryawan202@gmail.com
Abstract

The populist economic system which is based on kinship, democracy and justice encourages the Indonesian people to participate in capital ownership. Small and Medium Enterprises (SMEs'), which majority ownership of capital by local communities can be evidence of the application of the populist economy system in Indonesia. The study objective focuses on the concept of a populist economy system in empowering SMEs' in Indonesia. The study method is literature study with secondary data in the form of scientific articles and regulations that act as data sources. The results of the analysis show that in the current era of regional autonomy, the populist economy system for empowering SMEs' can be realized by raising local potential in order to increase regional economic independence. Empowerment of SMEs' based on a populist economy system must be a priority in enhancing national development, because it is proven that the SMEs' sector is able to withstand any climate change, including in crisis conditions. With the foundation of the spirit of the populist economy system ideology from interested parties, SMEs' can develop and improve Indonesia's national economy.

Abstrak
Sistem Ekonomi Kerakyatan yang berasaskan pada kekeluargaan,
demokratis dan berkeadilan mendorong rakyat Indonesia untuk ikut serta
dalam kepemilikan modal. Usaha mikro, kecil, dan menengah (UMKM)
yang mayoritas kepemilikan modal oleh masyarakat daerah dapat menjadi
bukti berlakunya sistem Ekonomi Kerakyatan di Indonesia. Tujauan
penelitian terfokus pada konsep sistem Ekonomi Kerakyatan dalam
pemberdayaan UMKM di Indonesia. Metode penelitian yaitu studi literatur
dengan data sekunder berupa artikel-artikel ilmiah dan peraturan yang
berlaku sebagai sumber data. Hasil analisis menunjukkan bahwa dalam era
otonomi daerah saat ini, sistem Ekonomi Kerakyatan untuk pemberdayaan
UMKM dapat diwujudkan dengan mengangkat potensi lokal agar dapat
meningkatkan kemandirian ekonomi daerah. Pemberdayaan UMKM yang
berdasar pada sistem Ekonomi Kerakyatan sudah harus menjadi prioritas
dalam meningkatkan pembangunan nasional, karena terbukti sektor
UMKM mampu bertahan pada setiap perubahan iklim ekonomi termasuk
dalam kondisi krisis. Dengan landasan semangat ideologi sistem Ekonomi
Kerakyatan dari pihak-pihak berkepentingan, maka UMKM dapat
berkembang dan meningkatkan perekonomian nasional Indonesia.

Fakultas Ekonomi dan Bisnis Universitas Udayana, Bali, Indonesia ${ }^{2}$

Email: suyanautama@gmail.com 


\section{PENDAHULUAN}

Pariwisata adalah salah satu sumber pendapatan utama dan penghasil devisa di Indonesia. Pariwisata juga berperan dalam penyerapan tenaga kerja dan pemberdayaan usaha mikro dalam yang tinggi pada daerah-daerahtujuan wisata maupun daerah-daerah lain. Pariwisata dewasa ini merupakan salah satu industri terbesar di dunia dan merupakan salah satu sektor ekonomi yang tumbuh paling cepat (Bhutia, 2015). Pulau Bali merupakan tujuan wisata terbesar di Indonesia dan sudah sangat terkenal di seluruh dunia. Industri pariwisata di Bali merupakan salah satu industri utama yang menopang kesejahteraan masyarakat di Bali (Margareni et al., 2016). Berdasarkan data dari BPS 2018 diketahui bahwa PRDB perkapita pada Kabupaten Gianyar meningkat secara konsisten setiap tahunnya. Hal tersebut menunjukkan bahwa Kabupaten Gianyar mempunyai potensi yang sangat besar untuk mengembangkan pembangunan terutama di sektor wisata agar dapat menarik minat wisatawan untuk berkunjung. Pemberdayaan masyarakat perlu dilakukan untuk menunjang pariwisata pada objek-objek wisata di Gianyar dimana masyarakat paling memahami tentang budaya wilayahnya yang merupakan daya tarik wisata di Bali, sehingga selanjutnya akan mampu menunjang PDRB di Kabupaten Gianyar.

Konsisi sosial masyarakat berperan penting dalam mencapai kemakmuran (Bhudianto, 2012). Sisem ekonomi yang diterapkan di Indonesia berlandasankan atas asas Pancasila (Mubyarto, 2014). Dalam sistem ekonomi Indonesia sangat menjunjung adanya keadilan dan kesejahteraan masyarakat (Malau, 2016). Masalah kesenjangan ekonomi masih terjadi sampai saat ini di Kabupaten Gianyar terutama pada pedesaan. Observasi awal yang dilakukan terhadap beberapa warga ditemukan bahwa hampir seperdelapan penduduk Desa Tegallalang masih menganggur. Hal tersebut menyebabkan kemampuan ekonomi terutama bagi masyarakat yang pengangguran masih lemah dan belum mampu menunjang kebutuhan hidup yang layak. Keadaan ini menunjukkan bahwa masih terdapat kesenjangan ekonomi pada masyarakat di Desa Tegallalang. Ketersediaan lapangan pekerjaan merupakan faktor penting untuk mengatasi hal tersebut, namun dapat juga dilakukan dengan menciptakan peluang sendiri salah satunya dengan mengoptimalkan objek wisata yang ada(Findlay \& Pangestu, 2016). Desa Tegallalang, Gianyar merupakan kawasan yang sering dikunjungi wisatawan baik domestik maupun internasional, karena merupakan salah satu pusat kerajinan tangan dan souvenir di Bali. Sebagian besar masyarakat mengembangkan industri kerjaninan tangan dengan mendirikan artshop di sepanjang jalan Tegallalang. Seiring berkembangnya pariwisata, saat ini mulai berkembang wahana-wahan baru sebagai sumber mata pencaharian masyarakat, diantaranya agro-wisata, restaurant, penginapan, dan pengembangan objek wisata lama yaitu Ceking Rice Terrace.

Konsep pariwisata berbasis $C B T$ yaitu keberlanjutan ekosistem, menghormati sosial budaya masyarakat dan memberikan manfaat ekonomi yang berkelanjutan kepada stakeholders atau pemangku kepentingan sangat cocok diterapkan di daya tarik wisata Ceking rice terrace, karena masalah yang terjadi dan terlihat sekarang sangat mengancam keberlanjutan aktifitas pariwisata di daya tarik wisata tersebut. Selain itu, pelayanan prima merupakan hal penting dalam menunjang keberlanjutan pariwisata. Di masa yang akan datang apabila pengelola tidak memiliki rumusan strategi yang tepat, hal ini menjadi suatu masalah dalam pengelolaan dan pengembangannya sebagai daya tarik wisata untuk mewujudkan pariwisata berkelanjutan(Sunuantari, 2017). Pariwisata berbasis komunitas memberikan peluang yang lebih besar bagi partisipasi komunitas lokal untuk melibatkan diri di dalam proses pengambilan keputusan-keputusan dan di dalam menikmati keuntungan perkembangan industri pariwisata, dan oleh karena itu lebih memberdayakan masyarakat(Jannah et al., 2018). Konsep yang

Pengaruh Pemberdayaan Masyarakat Terhadap Community Based Tourism Dan Kesejahteraan Masyarakat Pada Ceking Rice Terrace, Tegallalang, Adi Suryawan dan Made Suyana Utama 
digunakan dalam CBT juga sangat erat kaitannya dengan pemberdayaan, dimana masyarakat diberdayakan terlebih dahulu agar mampu mengembangkan potensinya sendiri, dengan pemberdayaan masyarakat yang dilatih untuk bisa menolong dirinya sendiri (self help), sehingga pada pembangunan objek wisata, masyarakat dikembangkan serta diberdayakan untuk mampu mengelola objek wisata sendiri(Anuar, 2017)

Menurut Mayaka et al. (2018), CBT menunjukkan kesejajaran yang jelas dengan pengembangan komunitas yang lebih luas dan filosofi perencanaan partisipatif, yang juga mengadvokasi kontrol komunitas proses di tingkat lokal. Dengandemikian, dalam CBT peran masyarakat lokalsebagai pemangku kepentingan merupakanunsur terpenting dalam pengembangan objek wisata(Giampiccoli \& Saayman, 2018)serta kesadaran, komunikasi, dan partisipasi tetap merupakan unsur utama pemberdayaan masyarakat (Witchayakawin et al., 2020).

Pengembangan industri pariwisata yang berbasis pada sustainable oriented model sudah mulai banyak dikembangkan di Bali dan salah satu daerah yang sudah menjadikan sustainable oriented model sebagai dasar dalam mengembangkan kawasannya adalah Tegallalang, Gianyar, Bali. Meskipun destinasi seperti Tegallalang telah memberikan dampak ekonomi terhadap masyarakat lokal, menjadi menarik untuk diukur seberapa signifikan model pengembangan pariwisata tersebut memberikan dampak positif terhadap kesejahteraan masyarakat lokal.

\section{METODE PENELITIAN}

Desain penelitian ini merupakan menggunakan pendekatan kuantitatif yang berbentuk asosiatif. Penelitian ini dilakukan di di Desa Tegallalang, Kecamatan Tegallalang, Kabupaten Gianyar karena merupakan salah satu desa yang ada di Kabupaten Gianyar yang cukup terkenal karena memiliki pemandangan yang indah dengan objek wisata yang sedang berkembang pesat yaitu Ceking Rice Terrace. Objek penelitian ini adalah pengaruh pemberdayaan masyarakat terhadap communitybased tourism dalam meningkatkan kesejahteraan masyarakat pada Objek Wisata Ceking Rice Terrace, Tegallalang, Gianyar. Sampel diambil dengan teknik simple random sampling, dengan jumlahnya mencapai 88 orang responden. Data kuantitatif dalam penelitian ini berupa hasil dari kuesioner yang disebarkan oleh peneliti. Dalam penelitian ini, data primer meliputi jawaban dari responden terhadap pernyataan dalam kuesioner yang dikumpulkan dari masyarakat lokal di Desa Tegallalang terkait objek wisata Ceking Rice Terrace dan sumber data sekunder dalam penelitian ini antara lain gambaran umum dan struktur kepengurusan Desa Tegallalang. Metode pengumpulan data yang digunakan dalam penelitian ini adalah observasi dimana peneliti melakukan pengamatan langsung. Dalam penelitian ini di gunakan analisis persamaan strukturan (SEM) dengan alternatif Partial Least Square PLS (komponen base SEM).

\section{HASIL DAN PEMBAHASAN}

Responden yang berjenis kelamin laki-laki sebanyak 45 orang atau $51,1 \%$ dan responden yang berjenis kelamin perempuan sebanyak 43 orang atau $48,9 \%$. Hal ini menjelaskan bahwa responden penelitian cukup berimbang antara laki-laki dan perempuan atau tidak memandang jenis kelamin. Jumlah responden terbanyak berdasarkan usia pada penelitian ini adalah pada kategori 40-49

Pengaruh Pemberdayaan Masyarakat Terhadap Community Based Tourism Dan Kesejahteraan Masyarakat Pada Ceking Rice Terrace, Tegallalang, Adi Suryawan dan Made Suyana Utama 
tahun yaitu sebanyak 29 orang atau 33,0\%. Hal tersebut menunjukkan bahwa responden sudah berusia dewasa namun masih dalam golongan umur yang produktif, sehingga dianggap mengetahui tentang keadaan Ceking Rice Terrace dan perkembangannya. Jumlah responden terbanyak berdasarkan tingkat pendidikan pada penelitian ini adalah yang memiliki pendidikan SMA yaitu sebanyak 34 orang atau 38,6\%. Hal tersebut menunjukkan responden memiliki tingkat pendidikan yang memadai, sehigga dianggap mampu memahami dan menjawab kuesioner dengan baik.

Distribusi frekuensi jawaban responden dari 5 instrumen variabel kesejahteraan masyarakat tergolong dalam kategori baik dengan rata-rata skor 2.97. Pendapatan memiliki rata-rata skor 2.86 dan tergolong dalam kategori baik, berarti pendapatan dipersepsikan cukup memadai oleh responden karena adanya objek wisata Ceking Rice Terrace.Kesehatan memiliki rata-rata skor 2.93 dan tergolong dalam kategori baik, berarti pemenuhan kesehatan dipersepsikan cukup terpenuhi oleh responden karena adanya objek wisata Ceking Rice Terrace.Pendidikan memiliki rata-rata skor 3.07 dan tergolong dalam kategori baik, berarti pemenuhan kebutuhan pendidikan dipersepsikan cukup terpenuhi oleh responden karena adanya objek wisata Ceking Rice Terrace.Tabungan memiliki rata-rata skor 3.01 dan tergolong dalam kategori baik, berarti tabungan yang dimiliki masyarakat dipersepsikan cukup memadai oleh responden karena adanya objek wisata Ceking Rice Terrace.Keharmonisan memiliki rata-rata skor 2.95 dan tergolong dalam kategori baik, berarti keharmonisan di antara masyarakat dipersepsikan cukup baik oleh responden karena adanya objek wisata Ceking Rice Terrace.

Distribusi frekuensi jawaban responden dari 3 instrumen variabel pemberdayaan masyarakat tergolong dalam kategori baik dengan rata-rata skor 2.99. Penyadaran memiliki rata-rata skor 2.86 dan tergolong dalam kategori baik, berarti sosialisasi dan pelatihan yang diberikan dipersepsikan cukup memadai oleh responden terkait objek wisata Ceking Rice Terrace.Pelaksanaan memiliki rata-rata skor 2.93 dan tergolong dalam kategori baik, berarti keterlibatan masyarakat dalam penyediaan fasilitas dipersepsikan sudah cukup baik oleh responden terkait objek wisata Ceking Rice Terrace.Pemberian daya memiliki rata-rata skor 3.17 dan tergolong dalam kategori baik, berarti bantuan pemerintah baik fisik maupun finansial dipersepsikan sudah cukup memadai oleh responden terkait objek wisata Ceking Rice Terrace.

Distribusi frekuensi jawaban responden dari 4 instrumen variabel community based tourism tergolong dalam kategori baik dengan rata-rata skor 3.09. Keterlibatan memiliki rata-rata skor 3.10 dan tergolong dalam kategori baik, berarti masyarakat dipersepsikan cukup sering terlibat dalam manajemen pariwisata Ceking Rice Terrace. Monitoring memiliki rata-rata skor 3.08 dan tergolong dalam kategori baik, berarti monitoring yang dilakukan masyarakat dipersepsikan cukup baik terhadap Ceking Rice Terrace.Kepemilikan memiliki rata-rata skor 3.10 dan tergolong dalam kategori baik, berarti kepemilikan masyarakat atas fasilitas objek wisata dipersepsikan cukup tinggi pada Ceking Rice Terrace.Manfaat memiliki rata-rata skor 3.08 dan tergolong dalam kategori baik, berarti manfaat yang diperoleh masyarakat dipersepsikan cukup tinggi oleh responden karena adanya objek wisata Ceking Rice Terrace.

Pendekatan PLS menspesifikasikan hubungan antar variabel, antara lain: 1) outer model, 2) inner model dan 3) pengaruh tidak langsung. Hasil analisis SEM dengan pendekatan PLS pada penelitian ini ditunjukkan oleh Gambar 1

Pengaruh Pemberdayaan Masyarakat Terhadap Community Based Tourism Dan Kesejahteraan Masyarakat Pada Ceking Rice Terrace, Tegallalang, Adi Suryawan dan Made Suyana Utama 


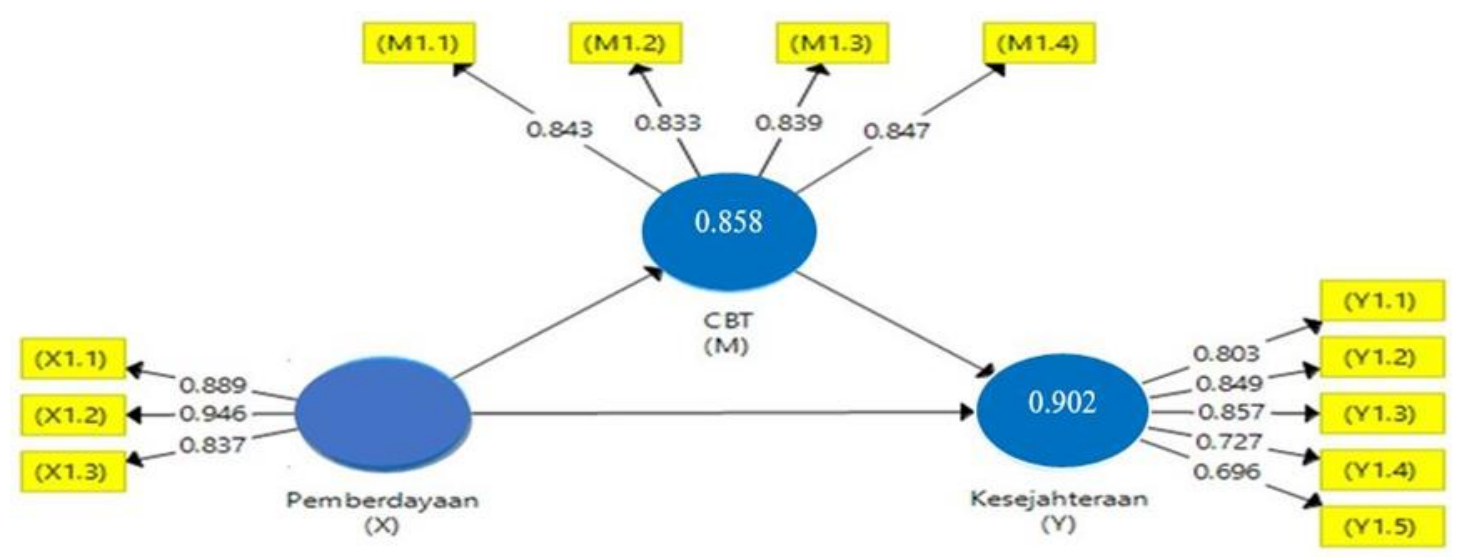

Sumber : Data Diolah, 2020

\section{Gambar 1. \\ Model PLS Penelitian}

Tabel 1.

Total Effect

\begin{tabular}{lcccc}
\hline & Original Sample & Standard Deviation & T Statistics & P Values \\
\hline Pemberdayaan (X) -> CBT (M) & 0.680 & 0.064 & 10.551 & 0.000 \\
Pemberdayaan (X) -> Kesejahteraan (Y) & 0.855 & 0.022 & 38.359 & 0.000 \\
CBT (M) -> Kesejahteraan (Y) & 0.513 & 0.078 & 6.590 & 0.000 \\
\hline
\end{tabular}

Sumber : Data Diolah, 2020

Pengaruh pemberdayaan masyarakat terhadap CBT dilambangkan dengan $\mathrm{b} 1=0,680$ menunjukkan pemberdayaan masyarakat memiliki pengaruh positif atau searah terhadap CBT. Hal tersebut berarti semakin baik pemberdayaan masyarakat yang diterapkan maka CBT juga akan semakin baik. Nyata dan tidaknya atau signifikansi pengaruh pemberdayaan masyarakat terhadap CBT ditunjukkan dengan nilai t-statistik $=10,551>1,96$ dengan $p$-value $0,000<0,05$, yang berarti pemberdayaan masyarakat berpengaruh signifikan atau secara nyata terhadap CBT. Oleh karena itu, hipotesis yang menyatakan bahwa pemberdayaan masyarakat berpengaruh positif terhadap community based tourism pada Objek Wisata Ceking Rice Terrace, Tegallalang, Gianyar diterima dan sesuai dengan Mayaka et al. (2018) yang mengungkapkan bahwa pemberdayaan masyarakat yang optimal akan mengarah ke penerapan CBT di masa yang akan datang.

Pengaruh pemberdayaan masyarakat terhadap kesejahteraan masyarakat dilambangkan dengan $\mathrm{b} 2=0,506$ menunjukkan pemberdayaan masyarakat memiliki pengaruh positif atau searah terhadap kesejahteraan masyarakat. Hal tersebut berarti semakin baik pemberdayaan masyarakat yang diterapkan maka kesejahteraan masyarakat akan dapat tercapai. Nyata dan tidaknya atau signifikansi pengaruh pemberdayaan masyarakat terhadap kesejahteraan masyarakat ditunjukkan dengan nilai tstatistik $=6,727>1,96$ dengan $p$-value $0,000<0,05$, yang berarti pemberdayaan masyarakat berpengaruh signifikan atau secara nyata terhadap kesejahteraan masyarakat. Oleh karena itu, hipotesis yang menyatakan bahwa pemberdayaan masyarakat berpengaruh positif terhadap kesejahteraan masyarakat pada Objek Wisata Ceking Rice Terrace, Tegallalang, Gianyar diterima dan sesuai dengan

Pengaruh Pemberdayaan Masyarakat Terhadap Community Based Tourism Dan Kesejahteraan Masyarakat Pada Ceking Rice Terrace, Tegallalang, Adi Suryawan dan Made Suyana Utama 
Tisnawati (2016) yang menyatakan bahwa pemberdayaan masyarakat memiliki makna bahwa penyelenggaraan pemerintah dan pelaksanaan pembangunan di desa ditujukan untuk peningkatan taraf hidup dan kesejahteraan masyarakat melalui penerapan kebijakan, program, dan kegiatan yang sesuai dengan esensi masalah dan prioritas kebutuhan masyarakat.

Pengaruh CBT terhadap kesejahteraan masyarakat dilambangkan dengan b3 $=0,513$ menunjukkan CBT memiliki pengaruh positif atau searah terhadap kesejahteraan masyarakat. Hal tersebut berarti semakin baik penerapan CBT maka kesejahteraan masyarakat akan dapat tercapai. Nyata dan tidaknya atau signifikansi pengaruh CBT terhadap kesejahteraan masyarakat ditunjukkan dengan nilai t-statistik $=6,590>1,96$ dengan $p$-value $0,000<0,05$, yang berarti CBT berpengaruh signifikan atau secara nyata terhadap kesejahteraan masyarakat. Oleh karena itu, hipotesis yang menyatakan bahwa community based tourism berpengaruh positif terhadap kesejahteraan masyarakat pada Objek Wisata Ceking Rice Terrace, Tegallalang, Gianyar diterima dan sesuai dengan teori dari Rizkianto \& Topowijono (2018)yang menyatakan bahwa sasaran utama dari pengembangan kepariwisataan berbasis komunitas (CBT) haruslah meningkatkan kesejahteraan masyarakat setempat

Peran CBT dalam memediasi pengaruh pemberdayaan masyarakat terhadap kesejahteraan masyarakat ditunjukkan oleh nilai pengaruh tidak langsung (indirect effect) pemberdayaan terhadap kesejahteraan masyarakat melalui CBT, yaitu sebesar 0,346, yang berarti CBT memediasi secara positif pengaruh pemberdayaan terhadap kesejahteraan masyarakat. Nyata dan tidaknya atau signifikansi peran CBT sebagai pemediasi pemberdayaan terhadap kesejahteraan masyarakat ditunjukkan dengan nilai t-statistik $=5,173>1,96$ dengan $p$-value $0,000<0,05$, yang berarti CBT secara signifikan atau secara nyata mampu memediasi pengaruh pemberdayaan terhadap kesejahteraan masyarakat. Oleh karena itu, hipotesis yang menyatakan bahwa community based tourism memediasi pengaruh pemberdayaan masyarakat terhadap kesejahteraan masyarakat pada Objek Wisata Ceking Rice Terrace, Tegallalang, Gianyar diterima dan sesuai dengan teori dari Goh (2015)yang menyatakan bahwa CBT lebih mengutamakan peningkatan kesejahteraan masyarakat dengan penguatan pemberdayaan masyarakat melalui penyediaan lapangan pekerjaan, meminimalkan dampak lingkungan yang merugikan, meningkatkan dampak positif, dan meningkatkan partisipasi masyarakat lokal dalam proses pengambilan keputusan.

CBT sebagai pariwisata yang memperhitungkan aspek keberlanjutan lingkungan, sosial dan budaya dalam komunitas. CBT bertujuan untuk membangun serta memperkuat kemampuan organisasi pada masyarakat lokal(Zielinski et al., 2020). CBT bertujuan untuk melibatkan penduduk lokal dalam menjalankan dan mengelola proyek-proyek pariwisata kecil sebagai cara untuk mengurangi kemiskinan dan menyediakan sumber pendapatan alternatif bagi anggota masyarakat. CBT lebih mengutamakan peningkatan kesejahteraan masyarakat melalui penguatan pemberdayaan masyarakat dengan penyediaan lapangan pekerjaan, meminimalkan dampak lingkungan yang merugikan, meningkatkan dampak positif, dan meningkatkan partisipasi masyarakat lokal dalam proses pengambilan keputusan (Goh, 2015). Penelitian ini memberikan pedoman bagi Desa Adat Tegallalang dalam mengelola objek wisata utama yang dimilikinya yaitu Ceking Rice Terrace. Kesejahteraan masyarakat cukup meningkat dengan adanya objek wisata Ceking Rice Terrace. Keberlangsungan dari Ceking Rice Terrace dapat dijaga dengan pengoptimalan pemberdayaan masyarakat disertai dengan penerapan community based tourism, sehingga Ceking Rice Terrace untukkedepannya akan tetap berdampak positif pada segi ekonomi masyarakat, lingkungan serta wisatawan. Penelitian ini juga memberikan pedoman bagi pemerintah setempat agar meningkatkan perannya dalam pemberdayaan masyarakat terkait Ceking Rice Terrace, baik dalam memberikan sosialisasi dan pelatihan tentang pariwisata terhadap masyarakat serta memberikan bantuan dana maupun fisik untuk membantu meningkatkan sarana dan prasarana pariwisata pada objek wisata Ceking Rice Terrace.

Pengaruh Pemberdayaan Masyarakat Terhadap Community Based Tourism Dan Kesejahteraan Masyarakat Pada Ceking Rice Terrace, Tegallalang, Adi Suryawan dan Made Suyana Utama 


\section{SIMPULAN DAN SARAN}

Berdasarkan hasil analisis dan pembahasan yang telah diuraikan sebelumnya, maka dapat ditarik kesimpulan bahwa Pemberdayaan masyarakat berpengaruh positif terhadap community based tourism pada Objek Wisata Ceking Rice Terrace, Tegallalang, Gianyar. Hal tersebut berarti jika pemberdayaan masyarakat semakin baik, maka community based tourism juga akan semakin baik, dan begitupula sebaliknya. Pemberdayaan masyarakat berpengaruh positif terhadap kesejahteraan masyarakatpada Objek Wisata Ceking Rice Terrace, Tegallalang, Gianyar. Hal tersebut berarti jika pemberdayaan masyarakat semakin baik, maka kesejahteraan masyarakatakan semakin meningkat, dan begitupula sebaliknya. Community based tourism berpengaruh positif terhadap kesejahteraan masyarakatpada Objek Wisata Ceking Rice Terrace, Tegallalang, Gianyar. Hal tersebut berarti jika community based tourism semakin baik penerapannya, maka kesejahteraan masyarakatjuga akan semakin meningkat, dan begitupula sebaliknya. Community based tourism memediasi pengaruh pemberdayaan masyarakat terhadap kesejahteraan masyarakat pada Objek Wisata Ceking Rice Terrace, Tegallalang, Gianyar. Hal tersebut berarti kesejahteraan masyarakat akan tercapai jika dilakukannya pemberdayaan masyarakat yang disertai dengan penerapan CBT yang baik.

Berdasarkan hasil penelitian dan simpulan diatas, maka dapat diajukan saran bahwa kesejahteraan masyarakat di Desa Tegallalang masih belum merata yang ditunjukkan oleh masih terdapatnya masyarakat yang belum memiliki pekerjaan. Hal tersebut dapat diatasi dengan meningkatkan pemberdayaan masyarakat karena masih banyak implementasi masyarakat yang tidak ikut serta dalam pengembangan objek wisata khususnya Ceking Rice Terrace. Pemberdayaan tersebut dapat ditingkatkan dengan memberikan sosialisasi dan atau pelatihan pembentukan objek wisata kepada masyarakat setempat tentang pariwisata. Banyak masyarakat khususnya pengguna jalan raya yang berasal dari luar desa mengeluhkan kemacetan yang sering terjadi di Objek Wisata Ceking Rice Terrace. Pengelola objek wisata sebaiknya memperluas lahan parkir dan memperingatkan wisatawan agar tidak lagi parkir di bahu jalan agar masalah kemacetan dapat teratasi sehingga menguntungkan bagi setiap masyarakat lokal maupun masyarakat pengguna jalan dari luar desa. Penelitian selanjutnya sebaiknya dilengkapi dengan variabel lain di luar model penelitian, karena masih terdapat beberapa variabel lain yang dapat mempengaruhi kesejahteraan masyarakat terkait objek wisata seperti promosi pariwisata dan pengoptimalkan dana desa.

\section{REFERENSI}

Annah, E. U., Muryani, C., \& Rindarjono, M. G. (2018). Community-Based Tourism Development at Gajah Mungkur Wonogiri Tourist Attraction. IOP Conference Series: Earth and Environmental Science, 145(1), 0-7. https://doi.org/10.1088/1755-1315/145/1/012017

Bhudianto, Wahyu. (2012). Sistem Ekonomi Kerakyatan dalam Globalisasi Perekonomian. Transformasi, 14(22), 1-9.

Bhutia, S. (2015). Sustainable Tourism Development in Darjeeling Hills of West Bengal India: Issues and Challenges. Global Journal of Human-Social Science, 15(3), 460-466.

Findlay, C., \& Pangestu, M. (2016). The Services Sector as a Driver of Change: Indonesia's Experience in the ASEAN Context. Bulletin of Indonesian Economic Studies, 52(1), $27-53$. https://doi.org/dx.doi.org/10.1080/00074918.2016.1161499

Giampiccoli, A., \& Saayman, M. (2018). Community-based tourism development model and community participation. African Journal of Hospitality, Tourism and Leisure, 7(4), 1-27.

Pengaruh Pemberdayaan Masyarakat Terhadap Community Based Tourism Dan Kesejahteraan Masyarakat Pada Ceking Rice Terrace, Tegallalang, Adi Suryawan dan Made Suyana Utama 
Goh, H. C. (2015). Nature and Community Based Tourism (CBT) For Poverty Alleviation: A Case Study of Lower Kinabatangan, East Malaysia. GEOGRAFIA OnlineTM Malaysia Journal of Society and Space, 11(3), 42-52

Malau, Natalia Artha. (2016). Ekonomi Kerakyatan Sebagai Paradigma Dan Strategi Baru Dalam Pembangunan Ekonomi Indonesia. Jurnal Ilmiah “Research Sainis," 2(1), 1-8.

Margareni, N. P. A. P., Djayastra, I. K., \& Yasa, I. G. W. M. (2016). Faktor-Faktor Yang Mempengaruhi Kemiskinan Di Provinsi Bali. PIRAMIDA, 12(2), 1

Mayaka, M., Croy, W. G., \& Cox, J. W. (2018). Participation as motif in community-based tourism: a practice perspective. Journal of Sustainable Tourism, 26(3), 416-432. https://doi.org/10.1080/09669582.2017.1359278

Mubyarto. (2014). Ekonomi Karakyatan. Retrieved from http://library1.nida.ac.th/termpaper6/sd/2554/19755.pdf

Rizkianto, N., \& Topowijono. (2018). Penerapan Konsep Community Based Tourism Dalam Pengelolaan Daya Tarik Wisata Berkelanjutan (Studi Pada Desa Wisata Bangun, Kecamatan Munjungan, Kabupaten Trenggalek). Jurnal Administrasi Bisnis (JAB), 58(2), 322-331

Sunuantari, M. (2017). Tourism Communication in Community Based Tourism in Dieng Community, Central Java, Indonesia. Binus Business Review, 8(2), 149. https://doi.org/10.21512/bbr.v8i2.1894

Tisnawati, N. M. (2016). Partisipasi Kelas Menengah Dalam Pengentasan Kemiskinan Pedesaan di Kabupaten Gianyar. Piramida Jurnal Kependudukan Dan Pengembangan Sumber Daya Manusia, 7(2), 72-79

Witchayakawin, P., Aziz, Y. A., Mahomed, A. S. B. B., \& Abdullah, N. H. B. (2020). Factors on development of community-based tourism (cbt) in phitsanulok province of Thailand. Journal of Critical Reviews, 7(12), 75-85. https://doi.org/10.31838/jcr.07.12.12

Zielinski, S., Jeong, Y., Kim, S. Il, \& Milanés, C. B. (2020). Why community-based tourism and rural tourism in developing and developed nations are treated differently? A review. Sustainability (Switzerland), 12(15), 5-18. https://doi.org/10.3390/su12155938

Pengaruh Pemberdayaan Masyarakat Terhadap Community Based Tourism Dan Kesejahteraan Masyarakat Pada Ceking Rice Terrace, Tegallalang, Adi Suryawan dan Made Suyana Utama 